\title{
A rare case of pneumoperitoneum in non-tubed COVID-19 patient.
}

Hazem Ghaith ${ }^{1}$, Mhd Alzabibi², Fateh Kashkash ${ }^{3}$, Sarya Swed ${ }^{4}$, Hidar Alibrahim ${ }^{4}$, Bisher Sawaf $^{5}$, Shoaib Ahmad ${ }^{6}$, and Karam Motawea ${ }^{7}$

${ }^{1}$ Al-Azhar University Faculty of Medicine

${ }^{2}$ Syrian Private University Faculty of Medicine

${ }^{3}$ University of Aleppo

${ }^{4}$ University of Aleppo Faculty of Medicine

${ }^{5}$ Syrian Private University

${ }^{6}$ Punjab Medical College

${ }^{7}$ Alexandria University Faculty of Medicine

March 3, 2022

\begin{abstract}
We report a rare case of a 50-year-old female with covid19 presented to the emergency department where supplementary oxygen is delivered via non-invasive face mask ventilation. x-ray imaging performed the existence of pneumoperitoneum. CT scan was not applicable due to the advanced status of the paient.
\end{abstract}

\section{Hosted file}

manuscript.docx available at https://authorea.com/users/463321/articles/558443-a-rare-caseof-pneumoperitoneum-in-non-tubed-covid-19-patient 